\title{
Evolution Game Theory Analysis of the Improvement of Energy Efficiency Occurring in the Process of the Inter-Region Industry Transfer
}

\author{
Jingmin Wang ${ }^{1, a}$, Xue Zhao ${ }^{2, b, *}$ \\ ${ }^{1}$ Department of Economics and Management, North China Electric Power University, Baoding, \\ China \\ ${ }^{2}$ Department of Economics and Management, North China Electric Power University, Baoding, \\ China \\ awangjmtc@163.coml, bvkvk_6344@163.coml \\ ${ }^{*}$ Corresponding author
}

\begin{abstract}
Keywords: Inter-regional Industrial Transfer; Energy Efficiency Improvement; Revolution Game Theory; Beijing-Tianjin-Hebei.
\end{abstract}

\begin{abstract}
Inter-regional industrial transfer can promote the upgrading of industrial structure and optimization of energy structure, and can improve regional energy efficiency by controlling the decision-making behavior factors of government and transfer subject to enhance energy efficiency in regional industrial transfer. Considering the influencing factors, such as technical cost, government supervision cost, environmental benefit and the environmental cost that one party must pay, the asymmetric $2 \backslash 2$ non-cooperation repeated game of energy efficiency improvement in inter-regional industrial transfer between the government and enterprises is analyzed through revolution game theory. According the results, the role of the government could guide the enterprises to improve energy efficiency via formulating relevant policies. And this paper choose Beijing and Hebei in Beijing-Tianjin-Hebei Synergistic Development Planning for a case study.
\end{abstract}

\section{Introduction}

Located in the heart of the Bohai Sea in northeastern China, the Beijing-Tianjin-Hebei region is the largest and most dynamic region in the north of China. It is also the region with the most serious energy consumption and environmental problems. The "Beijing-Tianjin-Hebei Synergistic Development Program" promulgated in 2015 will make Beijing, Tianjin and Hebei attract the attention of the whole China and the whole world. However, the energy and environmental problems in Beijing, Tianjin and Hebei are becoming more and more serious. The high input and high consumption mode of production has seriously restricted the people's normal life. Industrial transfer is chance of the Beijing-Tianjin-Hebei region to change the mode of production, improve energy efficiency opportunities. It is important to improve energy efficiency and solve environmental problems by analyzing the influencing factors of government and industry transfer, which is enterprises, to make the decision-making behavior of energy efficiency and to make some suggestions.

Inter-regional industrial transfer, whether the transfer or the undertaking side, the transfer of industries can promote the local social and economic development [2]. Compared with the Yangtze River Delta and the Pearl River Delta, the Beijing-Tianjin-Hebei region is an emerging economic circle, which the regional economic development is still uneven. Its industrial clusters are scattered, and those could not form a complete industrial chain. So, to solve the problem of the overall low level of energy use is imminent. The reasonable control of the factors regarding improving energy efficiency during industrial transfer process could directly affect the results of energy efficiency after the transfer of industrial results. At present, the existing energy efficiency researches are mainly quantitative analysis, and the mainly using method is data envelopment analysis (DEA) method [35]. Based on energy input and output, this method could divide the energy efficiency into integrated technical efficiency, pure technical efficiency and scale efficiency. It is a scientific method for energy efficiency policy-making. Pan introduced the system theory into the field of energy efficiency 
research, and he regarded energy efficiency improvement as a complicated system engineering. On this basis, he explored the system goal, system structure and system development strategy of China's energy efficiency promotion system, and proposed the "geese-type energy efficiency promotion model" and "three-dimensional energy efficiency upgrade strategy". Energy efficiency research is a continuous process in time, with the characteristics of repetition and evolution. So some scholars applied the evolutionary economy theory to the field of energy efficiency research. Zhai and Xu studied the impact of the game between government and low-income peasants on energy efficiency based on evolutionary game theory, and concluded that government could guide peasants to choose energy-saving products and improve energy efficiency [7].

There is not enough researches on the energy efficiency improvement during inter-regional industrial transfer. And considering the repetition and evolution of energy efficiency, this paper establishes the game payoff matrix for that problem based on revolution game theory. This paper analyzes the mechanism of competition and cooperation in regional industrial transfer in Beijing and Hebei, which provides the most scientific basis for the formulation of government economic policies, and ensures that the goal of energy efficiency improvement in the process of industrial transfer could be better realized.

\section{Analysis of Influencing Factors and Mechanism of Energy Efficiency Improvement in Inter- Regional Industrial Transfer}

\subsection{Analysis of Influencing Factors}

In this paper, energy efficiency factors are mainly divided into government, technology and market factors. Government factors can include the incentives, penalties, and supervision department setting. Technical factors including the impact of industrial structure, technology level and energy consumption structure on energy efficiency; market factors include the use of the original technology costs and benefits, the use of new technologies, costs and benefits.

The fundamental driving force of inter-regional industrial transfer is to maximize the benefits between the transfers of the main body. The "rational person" hypothesis of economics holds that the main motivation of enterprise is to pursue the maximization of economic benefits. However, how to make their own interests the greatest in the process of improving energy efficiency. Clearly stated in the modern economic strategy, only the participation of the main co-operation would achieve "winwin" and the greatest benefits.

\subsection{Game Subject and Analytical Method}

In this paper, we assume that $\mathrm{A}$ and $\mathrm{B}$ are the main players in the game. A is the high energy consumption enterprise in the region with high level of economic development. And $\mathrm{B}$ is the government department with lower economic development level than $\mathrm{A}$. The game between $\mathrm{A}$ and $\mathrm{B}$ is the game that obtains higher benefit through industry transfer, the former can choose to " improve energy efficiency during transfer process " or "not improve energy efficiency during transfer process", hereinafter referred to as "improve" and "no improve". The latter can choose to "strictly monitor whether the company to improve energy efficiency" or "relax the supervision of enterprises to improve energy efficiency", hereinafter referred to as "strict" and "relax."

This paper assumes that the players are bounded rational. Evolutionary game theory holds that the strategy corresponding to stable equilibrium is evolutionary stable strategy, and the strategy must be fine Nash equilibrium.

There is an assumption that $\mathrm{A}$, which in a region with a high level of economic development, would move to B. If A chooses to improve energy efficiency in a variety of ways, it would receive financial subsidies from government B (a7). Otherwise, party B will impose a fine of a8. The cost of energysaving materials to buy is a1, and to improve the production technique needs a2. The cost of technology transfer in the process of industrial transfer (ie, the cost of continuing the use of the original technology in the industrial undertaking) is a3. The profit of using new materials and new technologies is a4. The profit of using the original technology is a5, and the environmental cost of 
using the original technology to bear is a6. When the government adopts the strict policies to manage transfer the enterprise, it will set up the supervision department. At this time, the cost of supervision will be emerging. The use of new materials and new technology will still affect the local environment, but this part of the environmental cost is b2, borne by the government. As for the environment cost of not to improve energy efficiency, in addition to the part of the burden on enterprises, the government also need to bear b3. Government would receive the tax (b4) created by transferring enterprise. At the same time, the transfer of high energy efficiency enterprises would help to provide the social benefits (b5). Government would fine for failing to improve energy efficiency, which is b6, when B government loosening management, it would not set up supervision department, and there will be c probability of management loopholes. And management loopholes would cause the loss of b7. According to the above information, $\mathrm{A}$ and $\mathrm{B}$ game payment matrix is as follows:

Table 1. the payoff matrix between $\mathrm{A}$ and $\mathrm{B}$

B

Strict

Relax

\begin{tabular}{|c|c|c|}
\hline Improve & $\begin{array}{l}\text {-b1-b2+b4+b5 - } \\
\mathrm{a} 1-\mathrm{a} 2+\mathrm{a} 4+\mathrm{a} 7\end{array}$ & $\begin{array}{c}(-b 2+b 5) c+(-b 3-b 7)(1-c)+b 4 \\
(-a 1-a 2+a 4+a 7) c+(-a 3+a 5)(1-c)\end{array}$ \\
\hline No improve & $\begin{array}{l}-a 1-a 2+a 4+a 7 \\
-a 3-a 6+a 5-a 8\end{array}$ & $-a 3+a 5+(-a 8+a 6){ }^{-b 3+b 4-b 7(1-c)+b 6}$ \\
\hline
\end{tabular}

Assuming that the probability of choosing " improve " for firm A is $x(0 \leq x \leq 1)$, the probability of choosing "no improve" is $1-x$, and the probability of selecting "strict" in government $B$ is $y(0 \leq y \leq 1)$, then the probability of selecting "relax " is "1-y".

The payoff of the strategy of improving energy efficiency during the inter-regional industry transfer is calculated as follows:

$$
E_{11}=y\left(-a_{1}-a_{2}+a_{4}+a_{7}\right)+(1-y)\left[\left(-a_{1}-a_{2}+a_{4}+a_{7}\right) c+\left(-a_{3}+a_{5}\right)(1-c)\right]
$$

The payoff of the strategy of not improving energy efficiency during the inter-regional industry transfer is calculated as follows:

$$
E_{12}=y\left(-a_{3}-a_{6}+a_{5}-a_{8}\right)+(1-y)\left[-a_{3}+a_{5}+\left(-a_{6}-a_{8}\right) c\right]
$$

So the average payoff is calculated as follows:

$$
E_{1 \mathrm{t}}=x E_{11}+(1-x) E_{12}
$$

Then the firm A's dynamic simulation equation is shown below:

$$
\begin{gathered}
F(x)=d x / d t=x\left(E_{11}-E_{1 t}\right) \\
=x(1-x)\left[y\left(a_{3}+a_{4}+a_{6}+a_{7}+a_{8}-a_{1}-a_{2}-a_{5}\right)(1-c)+c\right] \\
-x(1-x)\left(a_{3}-a_{7}\right) \\
F^{\prime}(x)=(1-2 x)\left\{\left[y\left(a_{3}+a_{4}+a_{6}+a_{7}+a_{8}-a_{1}-a_{2}-a_{5}\right)(1-c)+c\right]-\left(a_{3}-a_{7}\right)\right\}
\end{gathered}
$$

According to eq. (4), when $y=y^{*}=\frac{\left(a_{8}-a_{7}\right)}{\left(a_{8}+a_{4}+a_{6}+a_{7}+a_{8}-a_{1}-a_{2}-a_{5}\right)(1-c)}-\frac{c}{1-c}$, it is always right that $F(x)=0$, that is, the value of each $x$ are stable. Because of $0 \leq y \leq 1$,

$0 \leq a_{3}-a_{7} \leq a_{3}+a_{4}+a_{6}+a_{7}+a_{8}-a_{1}-a_{2}-a_{5}$. When

$y \neq y^{*}=\frac{\left(a_{8}-a_{7}\right)}{\left(a_{8}+a_{4}+a_{6}+a_{7}+a_{8}-a_{1}-a_{2}-a_{5}\right)(1-c)}-\frac{c}{1-c}$, then $x=0$ and $x=1$ are evolution stable strategies (ESS). When $y>\frac{\left(a_{8}+a_{4}+a_{6}+a_{7}+a_{8}-a_{1}-a_{2}-a_{5}\right)(1-c)}{\left(a_{8}+a_{4}+a_{6}+a_{7}+a_{8}-a_{1}-a_{2}-a_{5}\right)(1-c)}-\frac{c}{1-c}, F^{\prime}(1)<0, F^{\prime}(0)>0$, then $x=1$ is the ESS. When $y<\frac{\left(a_{8}-a_{7}\right)}{\left(a_{8}+a_{4}+a_{6}+a_{7}+a_{8}-a_{1}-a_{2}-a_{5}\right)(1-c)}-\frac{c}{1-c}, F^{\prime}(0)<0, F^{\prime}(1)>0$, then $x=0$ is ESS.

The same procedure may be adapted to obtain B's dynamic simulation equation:

$$
\begin{aligned}
F(y) & =d y / d t=y\left(E_{21}-E_{2 t}\right) \\
& =y(1-y)\left[x\left(b_{2}+b_{5}-b_{2}\right)(1-c)-b_{1}+b_{7}(1-c)\right] \\
F^{v}(y) & =(1-2 y)\left[x\left(b_{3}+b_{5}-b_{2}\right)(1-c)-b_{1}+b_{7}(1-c)\right]
\end{aligned}
$$

According to eq.(4), when $x=x^{*}=\frac{b_{1}-b_{7}(1-c)}{\left(b_{3}+b_{5}-b_{2}\right)(1-c)}$, it is always right that $F(y)=0$, that is, the value of each $x$ are stable. Because of $0 \leq x \leq 1,0 \leq b_{1} \leq\left(b_{a}+b_{5}+b_{7}-b_{2}\right)(1-c)$. When $x \neq x^{*}=\frac{b_{1}-b_{7}(1-c)}{\left(b_{3}+b_{5}-b_{2}\right)(1-c)}$ then $y=0$ and $y=1$ are evolution stable strategies (ESS). When 
$x>\frac{b_{1}-b_{7}(1-c)}{\left(b_{3}+b_{5}-b_{2}\right)(1-c)}, F^{v}(1)<0, F^{v}(0)>0$, then $y=1$ is the ESS. When $x<\frac{b_{1}-b_{7}(1-c)}{\left(b_{3}+b_{5}-b_{2}\right)(1-c)}, F^{v}(0)<0$, $F^{y}(1)>0$, then $y=0$ is ESS.

According to the changes on proportion of population type dynamic relationship between above two types, we could show the change trends in in $\mathrm{x}$ and $\mathrm{y}$ coordinates for the coordinate axis, which as shown in Figure 1 below. There are two stable equilibrium strategies in this game, which are $(x=$ $0, \mathrm{y}=0)$ and $(\mathrm{x}=1, \mathrm{y}=1)$. The corresponding stable equilibrium strategies are (no improve, relax) and (improve, strict)

When the initial situation falls in the region II, it will converge to the evolutionary stability strategy $(x=1, y=1)$. It means that A enterprise groups have chosen to "improve" and $\mathrm{B}$ government have chosen "strict". In the game, since both A and B are bounded rational groups, the probability of choosing "improve" or "no improve ", "strict" or "relax" all would be considered to be homogeneous on $(0,1)$. The areas of the I , II ,III,IV in the coordinate plane represent the probability that the initial selection case falling in each region, and its size depends on the size of $x^{*}$ and $y^{*}$.

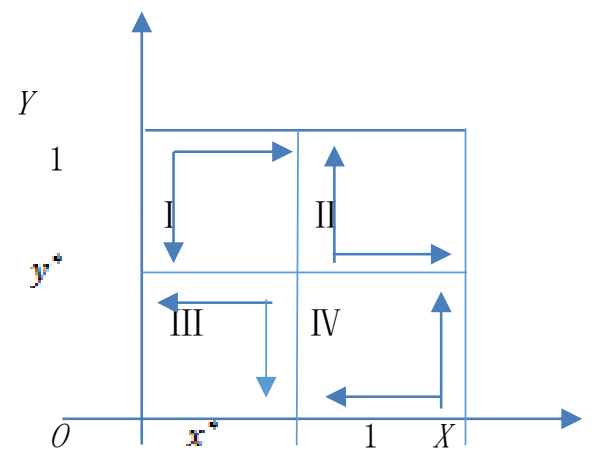

Fig.1 The dynamic process and stability diagram of the two parties in industrial transfer

\section{An Empirical Analysis of the Impact Factors of Energy Efficiency Improvement in Industrial Transfer}

\subsection{Environmental utility}

When $a_{6}, b_{a}$ increases, $b_{2}$ becomes smaller, $x^{*}, y^{*}$ are smaller. Compared to the traditional mode of production, energy-saving materials and new technologies could help to improve the energy efficiency. Its impact on the environment is small. Therefore, when the government increases the environmental cost that the enterprise does not improve the energy efficiency, $x^{*}$ becomes smaller. And the government chooses "strictly supervise" behaviour. The ESS is $(x=0, y=1)$ or $(x=1, y=1)$. When $b_{2}$ becomes smaller and $b_{a}$ increases, $y^{*}$ becomes smaller, enterprises prefer to choose "improve" strategy, the Nash equilibrium $(\mathrm{x}=1, \mathrm{y}=1)$ could be obtained.

\subsection{Economic effect of enterprises in inter-regional industrial transfer}

When $a_{1}, a_{2}$ and $a_{5}$ decrease, $a_{3}, a_{4}, a_{7}$ and $a_{8}$ increase, $y^{*}$ becomes smaller. Then the size of region II is also reduced. The costs of technological progress and energy conserving are relatively high. According to "economic man" hypothesis, the fundamental goal of firms is to seek profit. If traditional production processes and materials ensure its benefits $\left(a_{5}\right)$ could cover the cost of technology transfer $a_{3}$, at the same time, the government does not enhance the energy efficiency penalty $a_{8}$ and the environmental cost $a_{6}$, that the enterprise needs to bear in the industry transfer process, while the enterprise will not have the power to improve energy efficiency. When the subsidies $a_{7}$ is high enough, and firms would no longer bear the environmental costs, the technical costs $a_{1}, a_{2}$ would be reduced, and enterprises would obtain more benefit by using same energy. So the increase of subsidies and the reduction of technical cost are only the power to improve energy efficiency. 


\subsection{The economic effect of industry acceptance region}

As the party to undertake the industry, the local regional economy must need to be developed. Therefore, enterprises to enhance energy efficiency would contribute to reduce the environmental costs borne by the local government. The advanced level of technology and environmental ideas play the positive role in promoting economic sustainable development. For example, more high-energy production enterprises follow the development of new technologies and the use of new materials, etc. Or the upstream and downstream enterprises would improve energy efficiency based on the existing level of technology, which is technology spillover effect. The corresponding energy-saving environmental protection ideas can be extended to the whole society, thereby the community's overall awareness of emission reduction would be promoted. The social benefits are enormous.

\subsection{Government to monitor costs}

The supervision cost of government is high, which means that the payoff of government in this game becomes high. Then the government does not have the enthusiasm to supervise the enterprises' behaviour. From the quantitative point of view, when the cost of government oversight $\left(b_{1}\right)$ is too high, then $x^{*}$ would increase. When the size of the II region would be reduced, the choice of government gradually tend to be "relax management". However the company selected as "improve energy efficiency" or "no improve energy efficiency", the Nash equilibrium is $(x=0, y=0)$ or $(x=1$, $\mathrm{y}=0$ ). On the contrary, the Government needs to control the cost of monitoring inputs to ensure enterprises enhance energy efficiency at the same time. While their supervision efficiency also should be improved.

\section{Policies Recommendation}

\subsection{Reduce environmental cost}

To undertake industrial transfer, it is necessary to set the transferring standards of low-carbon enterprise to limit the transfer of high-carbon industries. Hebei should provide technical support to high-energy-consuming industries to reduce the technological improvement cost. It is also significant to develop energy-saving materials and encourage low-carbon production and consumption model. Ultimately, the reduction of environmental costs occurring inter-regional industrial transfer, and achieving environmental protection and economic development of a virtuous circle would come true.

\subsection{Improve the subsidy policy}

According to the results, effective incentives can promote the enterprises to make energy-efficient decisionmaking during inter-regional industry transfer. The subsidies can be used for energy-saving materials and technological progress. Only the subsidies to the main body to enhance energy efficiency are effectively implement, it is possible to achieve regional energy efficiency goals.

\subsection{Control the supervision cost of government}

Government intervention has a significant impact on regional energy efficiency [8]. There may be several kinds of supervision loopholes: enterprises receive government subsidies, the lack of enterprises to reduce energy consumption, including costs, including incentives, Energy consumption at the micro-level will increase; Finally, in order to promote economic growth, business and government interests alliances, the Government may be on the local enterprises of pollution behavior indulgence and indifference. Therefore, the government supervision departments should strictly manage the various industries in the process of industrial transfer behavior, reduce the loss caused by oversight loopholes, and urge enterprises to enhance energy efficiency.

\subsection{Construct regional market industry chain}

From the current point of view, to build a close, division of labor and orderly regional industrial value chain is conducive to the promotion of inter-regional industrial orderly transfer, and ultimately achieve the transfer process to improve energy efficiency. Such as energy-saving materials and energy-saving technologies in the promotion of the whole industry chain to avoid the existence of the traditional mode of production continuity. Specifically, to strengthen the construction of the industry chain between Beijing and Hebei could, avoid the 
re-use and waste of resources. The better form a rational division of labor and industrial linkage, the better promote technological development.

\section{References}

[1] Fan Ruguo. Game Theory [M]. Wuchang: Wuhan University Press, 2011.

[2] Q. Li and K.N. Xu, Study on industry transfer: a case study of Wanjiang metropolitan area, Journal of Xidian University, vol.03, pp. 61-65, 2009.

[3] X.P. Wang, P.H. Liu, and Y. Jiang, Empirical Analysis of Regional Difference in Energy Efficiency in Hebei Province Based on DEA Model, Demand Side Management, vol.05, pp. 21$25,2012$.

[4] Z.H. Zhang, Changes in Regional Energy Efficiency and Its Influencing Factors in China, Quantitative Technology and Economic Research, vol.8, pp. 73-88, 2015.

[5] D.Y. Li, Y. Sun, and G. Yang, .Environmental benefit, energy efficiency and economic performance of enterprises, Management Review, vol. 27, pp. 29-37, 2015.

[6] G.G. Pan and J.T. Jia, Study on China's Energy Efficiency Improvement Strategy Based on System Theory, Energy Conservation Technology, vol. 03, pp. 277-280, 2011.

[7] M.L. Zhai and X. Zhang, Evolutionary Game Theory Analysis of the Role of Government Regulation on the Rural Energy Efficiency Construction, vol. 263, pp. 631-639, 2014.

[8] B. Shi and K.R. Shen, Government intervention, economic agglomeration and energy efficiency, Management World, vol. 10, pp. 6-18, 2013.

[9] Z. Song, Analysis of the causes and effects of China's industrial transfer [D]. Wuhan University, 2013.

[10] Y.S. Tang, N.P. Feng, D.B. Gao, and S.L.Yang, Effects of Industry Transfer on Industrial Agglomeration: An Analysis Based on Pan-Yangtze River Delta Manufacturing Spatial Panel Model, Systems Engineering Theory \& Practice, vol. 10,pp. 2573-2581,2014. 